\title{
Industria maquiladora y cambio técnico
}

\section{Rudolf M. Buitelaar}

\section{Unidad de Desarrollo}

Industrial y Tecnológico,

División de Desarrollo

Productivo y Empresarial,

CEPAL

\section{Ramón Padilla Ruth Urrutia}

Funcionarios de la

Unidad de Industria,

Sede Subregional

de la CEPAL en México
Este artículo examina la ofensiva exportadora de México, Centroamérica y algunos países del Caribe desde mediados de los años ochenta. Pese a diferencias entre ellos, en todos los países mencionados ese impulso ha estado orientado principalmente al mercado de los Estados Unidos, ha sido estimulado por privilegios arancelarios para la importación y otros incentivos y ha sido producto de operaciones de ensamblado con baja remuneración. Se trata de lo que se ha dado en llamar las industrias maquiladoras. Aquí se intenta dilucidar si estas industrias contribuyen al desarrollo tecnológico local. La respuesta, basada en un cuestionario sometido a 75 empresas maquiladoras en seis países, ha de ser afirmativa. La industria maquiladora emplea técnicas de producción cercanas a las mejores prácticas internacionales, lo que sólo puede decirse de unas pocas empresas manufactureras locales.Además, las empresas maquiladoras contribuyen a la formación de recursos humanos e introducen modernos conceptos de organización y gestión. De otra parte, las actividades de maquila hacen uso intensivo de mano de obra poco calificada. Por lo tanto, para avanzar por la senda del desarrollo sostenible con equidad social, parece necesario transformar la maquila en una actividad cada vez más competitiva mediante el aumento de su productividad y del valor agregado de su producción. La evolución de las industrias maquiladoras hacia actividades que requieren una fuerza de trabajo más calificada es posible, como lo demuestra el caso mexicano, y se hará inevitable cuando las presiones sobre el mercado laboral hagan subir los salarios reales, como lo ilustra el caso de Costa Rica. Pero no sucederá automáticamente, y menos aún en países carentes de instituciones que respalden tal proceso. 


\section{I}

\section{Introducción}

La estructura y el desempeño de las exportaciones de México, Centroamérica y algunos países del Caribe han variado sobremanera en las dos últimas décadas. Estos países, que solían depender demasiado de las exportaciones de productos primarios, comenzaron a perder participación en el mercado de dichos productos. En la actualidad, exportan principalmente productos manufacturados y aumentan su participación de mercado aceleradamente. Al parecer, esto es precisamente lo que la opinión ortodoxa sugeriría que deben hacer esos países para alcanzar el desarrollo económico: aumentar su participación en el comercio internacional y modificar la composición de los productos exportados. La CEPAL también formuló orientaciones de política en este sentido (CEPAL, 1990).

¿Pero es esta ofensiva exportadora un buen motor del desarrollo? Existen distintas maneras de expandir las exportaciones de un país (CEPAL, 1990). Algunas pueden ser más conducentes al desarrollo que otras. La competitividad internacional puede lograrse a través de la reducción constante del salario real, a expensas del medio ambiente, o mediante subsidios que el gobierno otorga a las empresas al costo de aumentar los déficit fiscales. Puede que las exportaciones basadas en uno de esos factores no conduzcan al desarrollo sustentable. El extinto Fajnzylber, que había coordinado el estudio de la CEPAL, denominó a estas formas competitividad "espuria". Por otra parte, la competitividad internacional puede basarse en el incremento de la productividad, lo que exige un progreso técnico continuo. El mismo autor consideró que el cambio técnico era la única fuente "auténtica" de competitividad y la más conducente al desarrollo sustentable. Por lo tanto, las proposiciones formuladas por la CEPAL en 1990 perseguían incrementar la competitividad mediante el cambio técnico.

Considérese la ofensiva exportadora de los países ya mencionados desde mediados de los años ochenta. Naturalmente, hay diferencias conspicuas entre México, por una parte, y los países centroamericanos y caribeños por la otra. El presente artículo examinará

$\square$ Este artículo se basa en CEPAL (1998) y es una revisión del texto presentado en la $21^{\circ}$ Conferencia de la Asociación de Estudios Latinoamericanos, Chicago, 1998. esas diferencias con cierto detalle. Sin embargo, no cabe duda de que en todos ellos esa ofensiva exportadora ha sido i) orientada principalmente al mercado de los Estados Unidos; ii) estimulada por exenciones arancelarias y de impuestos locales, entre otros incentivos, y iii) el producto de operaciones de ensamblado de baja remuneración. Esto es lo que se ha dado en denominar "industria maquiladora", cuya definición no es muy precisa. En todo caso, los dos últimos puntos parecen encajar muy bien con la descripción de "competitividad espuria".

Desechar el éxito exportador de estos países por basarse en la "competitividad espuria" y ser "menos conducente al desarrollo" sería también una conclusión demasiado precipitada. ¿Contribuye en algo la industria maquiladora al progreso tecnológico? ¿Hay cambio tecnológico en la industria maquiladora? En caso de no ser todavía un signo de competitividad "auténtica”, ¿podría tal vez conducir a ella? Esos son los interrogantes que este artículo se aventura a responder.

Luego de haber aplicado un cuestionario a alrededor de 75 empresas maquiladoras de seis países, ${ }^{1}$ estamos en condiciones de describir con algún detalle la transferencia de tecnología y los procesos de aprendizaje. Surgieron diferencias manifiestas entre la experiencia mexicana y la de los cinco países restantes. Asimismo, se encontraron diferencias entre las empresas con capital de origen nacional distinto. En suma, concluimos que hay cierta forma, aunque bastante limitada, de transferencia de tecnología y un mejoramiento de las capacidades productivas locales, gracias a la maquila. Este aspecto se ha pasado más bien por alto en las estrategias de desarrollo de esos países, en los que la maquila se considera sobre todo un mecanismo generador de empleo y hasta cierto punto también un generador de divisas. Rara vez se la ha visto como una fuente para mejorar las capacidades productivas y tecnológicas. Nuestra propuesta es que la maquila debería considerarse también como una estrategia para desarrollar las capacidades productivas, lo que implicaría un enfoque normativo diferente de la maquila.

\footnotetext{
${ }^{1}$ México, cuatro países centroamericanos (Costa Rica, Guatemala, El Salvador y Honduras) y un país caribeño (la República Dominicana).
} 
Este artículo continúa en la sección II con la presentación de datos de comercio exterior que revelan el cambio en la inserción internacional de los países examinados cuya industria maquiladora ha crecido con rapidez durante los años noventa. En la sección III, se define el término industria maquiladora y se describe su crecimiento. En la sección IV, la más importante, se presentan los resultados del análisis del cuestionario, y en la sección V se formulan algunas observaciones y reflexiones finales en materia de políticas.

\section{II \\ Desempeño y composición de las exportaciones}

En esta sección utilizaremos el mismo tipo de información y metodología propuesto por Fajnzylber (1991). ${ }^{2}$ Esta metodología ilustra bien el cambio drástico en la inserción internacional de las economías en cuestión. Primero, considera la participación de mercado del grupo de países considerados en las importaciones totales de los países industrializados. El cuadro 1 muestra que estos países, como grupo, elevaron su participación de mercado entre 1989 y 1995 a un ritmo comparable con el de los países exitosos del Asia sudoriental.

Después, nos ceñiremos al criterio de Fajnzylber (1991) para analizar este desempeño exportador en dos dimensiones: la calidad de la combinación de productos exportados y la competitividad (definida como la capacidad de ganar participación en el mercado) por grupo de productos. Sirviéndose de una forma más bien simple de análisis de participación constante de mercado, Fajnzylber presentó una matriz inspirada en la tipología introducida por el Boston Consulting Group. Con ella, ideó un conjunto simple de indicadores que utilizó como sustitutos de la competitividad y la calidad de la combinación de bienes exportados.

En notación algebraica, los indicadores se definen como sigue. La variación de la participación de mercado del país $i$ en las importaciones $M$ del grupo de productos $j$ efectuadas por la Organización de Cooperación y Desarrollo Económicos (OCDE) entre el año base $b$ y el año final $f$, se expresa como sigue:

$$
(\operatorname{Mij}(f) / M j(f))-(M i j(b) / M(b))
$$

\footnotetext{
2 Es necesario utilizar la información sobre las importaciones de los países industrializados en vez de los datos sobre las exportaciones, ya que las exportaciones de las maquiladoras no siempre están bien registradas en estos últimos.
}

\begin{tabular}{lccc} 
CUADRO 1 & \multicolumn{3}{c}{$\begin{array}{l}\text { Algunas regiones y países: Participación } \\
\text { en las importaciones de países } \\
\text { industrializados, varios años } \\
\text { (En porcentaje) }\end{array}$} \\
& América & Tigres & México, Centroamérica \\
& Latina & asiáticos $^{\text {a }}$ & y República Dominicana \\
\hline Año & 5.21 & 6.52 & 1.47 \\
& 6.16 & 8.34 & 2.32 \\
1977 & 4.61 & 9.68 & 1.74 \\
1984 & 4.97 & 12.66 & 2.48 \\
1989 & & &
\end{tabular}

Fuente: Base de datos CANPLUS, de la CEPAL.

a Corea del Sur, Hong- Kong, Taiwán y Singapur.

Si la fórmula da un resultado positivo, el país $i$ es un "ganador" en el mercado de la OCDE para el grupo de productos $j$. Si es negativo, el país $i$ perdió participación en el mercado.

La variación de la participación del producto para cada producto $j$ en el total de importaciones de la OCDE se expresa como sigue:

$$
(M j(f) / M(f))-(M j(b) / M(b))
$$

Si la segunda fórmula da un valor positivo, las importaciones del grupo de productos $j$ crecieron con más rapidez que las importaciones totales. Se puede decir que este es un grupo de productos cuya demanda tiene un crecimiento dinámico, o simplemente que se trata de "productos dinámicos". En cambio, un valor negativo indica "productos estancados". Cabe señalar que Fajnzylber asumió implícitamente una correlación positiva entre los "productos dinámicos" y los "productos con uso intensivo de tecnología" o "nuevos". El ejercicio puede realizarse en una matriz de dos 
por dos, en que la fórmula 1 se sitúa en el eje vertical y la fórmula 2 en el eje horizontal (gráfico 1).

La suma total de todos los productos en las cuatro categorías del país $i$ es igual a las exportaciones totales de ese país al mercado (Mi) de la OCDE. Ahora, hay que calcular dos indicadores.

La relación $(\Sigma R S+\Sigma D S) / M i$ puede considerarse un indicador de competitividad, dado que refleja el porcentaje del valor total de exportación de los productos en los cuales el país $i$ gana participación en el mercado. Fajnzylber denominó esto "eficiencia", y es un sustituto de la "competitividad" revelada.

La relación $(\Sigma R S+\Sigma L O) / M i$ puede considerarse un indicador de la calidad de la combinación de productos exportados, dado que refleja el porcentaje del valor total de las exportaciones que corresponde a productos dinámicos. Fajnzylber llamó a esto "posicionamiento". Tanto los indicadores de eficiencia como de posicionamiento pueden variar en teoría entre 0 y 100 . El indicador de eficiencia es 0 si el país perdió participación de mercado en todos los productos que exportaba a la OCDE; y es 100 si ganó participación de mercado en todos ellos. El indicador de posicionamiento será 0 si todos los mercados de productos en que el país participaba crecieron menos que el crecimiento de las importaciones totales de la OCDE, y será 100 si todos los mercados de productos crecieron sobre el promedio.

En el cuadro 2 figura tanto el período 1979-1988 (Fajnzylber, 1991) como la actualización hasta 1995 efectuada para este artículo. En él se ve que ya en 1988 México y la República Dominicana ${ }^{3}$ obtenían un alto puntaje en ambos indicadores, y que posteriormente, hasta 1995, estos países mejoraron ligeramente su buen desempeño. También Costa Rica ya era un país "ganador" en 1988, más debido a su competitividad (94\% de sus exportaciones totales eran productos en los que
CUADRO 2

\begin{tabular}{lccc} 
& $\begin{array}{l}\text { México, cuatro países centroamericanos } \\
\text { y la República Dominicana: Eficiencia y } \\
\text { posicionamiento, 1979-1988 y 1989-1995 } \\
\text { (Porcentajes) }\end{array}$ \\
\hline País & Años & Eficiencia & Posicionamiento \\
\hline México & $1979-1988$ & 83 & 64 \\
Guatemala & $1989-1995$ & 84 & 65 \\
& $1979-1988$ & 39 & 24 \\
El Salvador & $1989-1995$ & 93 & 71 \\
& $1979-1988$ & 8 & 26 \\
Honduras & $1989-1995$ & 92 & 94 \\
& $1979-1988$ & 41 & 24 \\
Costa Rica & $1989-1995$ & 81 & 80 \\
& $1979-1988$ & 94 & 38 \\
República & $1989-1995$ & 94 & 61 \\
Dominicana & $1979-1988$ & 74 & 80 \\
\hline
\end{tabular}

Fuente: Base de datos CANPLUS, de la CEPAL.

Costa Rica ganaba participación de mercado) que a su buen posicionamiento. ${ }^{4}$ De hecho, también en el período siguiente los productos "estancados" fueron el pilar de las exportaciones costarricenses. En estos tres países la industria maquiladora empezó a crecer a comienzos de los años ochenta, lo que explica gran parte de los indicadores de buen desempeño en 1988.

En los tres países centroamericanos restantes se observa un cambio espectacular de la situación. Después de figurar entre los exportadores con peor desempeño del mundo en los años ochenta, pasaron a situarse entre los mejores. No sólo desplazaron a los competidores de los mercados de productos en que participan, sino que los grupos de productos que exportan encaran una demanda dinámica (las importacio-

GRAFICO 1

La matriz de competitividad

\begin{tabular}{|c|c|}
\hline $\begin{array}{c}\text { Estrellas menguantes } \\
\text { Productos estancados en los cuales el país } i \\
\text { gana participación de mercado }\end{array}$ & $\begin{array}{c}\text { Estrellas nacientes } \\
\text { Retrocesos } \\
\begin{array}{c}\text { Productos estancados en los cuales el país } i \text { pierde } \\
\text { participación de mercado }\end{array}\end{array}$ \\
$\begin{array}{c}\text { Productos dinámicos en los cuales el pana } \\
\text { participación de mercado }\end{array}$ \\
$\begin{array}{c}\text { Oportunidades perdidas } \\
\text { Productos dinámicos en que el país } i \text { pierde participación } \\
\text { de mercado }\end{array}$ \\
\hline
\end{tabular}

3 Respecto a la República Dominicana véase, por ejemplo, Mortimore, Duthoo y Guerrero (1995).
4 Mortimore y Zamora (1998) ofrecen información detallada sobre las exportaciones de vestuario costarricenses. 
nes estadounidenses de estos productos crecen más rápido que el promedio).

¿Podrá este desempeño impresionante, tanto en términos de mayor participación de mercado como en términos de una mejor combinación de productos exportados, conducir a un desarrollo sustentable? A juicio de la CEPAL, esto es posible si se basa en el cambio técnico y el aumento de la productividad. En este artículo se analiza en particular la contribución que han hecho al cambio técnico las exportaciones de las maquiladoras, y se destaca la magnitud de tales exportaciones como porcentaje de las exportaciones totales, tanto respecto de México (cuadro 3) como de Centroamérica y la República Dominicana (cuadros 4 y 5). Las estadísticas mexicanas, que distinguen las exportaciones de las maquiladoras de las demás exportaciones, muestran que la participación de la maquila en las exportaciones totales aumentó de $11-15 \%$ a comienzos de los años ochenta a alrededor de $40 \%$ en los noventa. Evidentemente, las exportaciones de las empresas maquiladoras han crecido mucho más rápido que las demás exportaciones.

Los datos nacionales de Centroamérica y la República Dominicana no incorporan las exportaciones de las maquiladoras. Los datos sobre las importacio- nes de los Estados Unidos sí lo hacen, pero sólo se dispone de información a contar de 1990 en adelante (debido a la introducción del Sistema Armonizado). Si se restan de las importaciones estadounidenses originadas en Centroamérica y la República Dominicana las

\begin{tabular}{lccc} 
CUADRO 3 & \multicolumn{3}{c}{$\begin{array}{l}\text { México: Exportaciones de la maquila } \\
\text { como porcentaje de las exportaciones } \\
\text { totales }\end{array}$} \\
& a, 1980-1988 & \\
\hline Año & Porcentaje & Año & Porcentaje \\
\hline 1980 & 14.0 & 1989 & 35.1 \\
1981 & 13.8 & 1990 & 34.1 \\
1982 & 11.7 & 1991 & 37.1 \\
1983 & 14.0 & 1992 & 40.4 \\
1984 & 16.9 & 1993 & 42.1 \\
1985 & 19.0 & 1994 & 43.1 \\
1986 & 25.9 & 1995 & 39.1 \\
1987 & 25.7 & 1996 & 38.5 \\
1988 & 33.1 & 1997 & 40.9 \\
\hline
\end{tabular}

Fuente: Banco de México, varios años, http://www.banxico. org.mex.

a Tanto las exportaciones de la maquila como las exportaciones totales están expresadas en valores FOB, y representan el valor bruto de la producción. Las exportaciones de la maquila son aquellas exportaciones registradas en la partida "programa de las maquiladoras".

CUADRO 4

Centroamérica y República Dominicana: Exportaciones de la maquila como porcentaje de las exportaciones totales a los Estados Unidos a, 1990-1997

\begin{tabular}{|c|c|c|c|c|c|c|c|c|}
\hline & 1990 & 1991 & 1992 & 1993 & 1994 & 1995 & 1996 & 1997 \\
\hline Costa Rica & 39.9 & 36.8 & 40.2 & 46.3 & 41.5 & 44.0 & 43.1 & $\ldots$ \\
\hline El Salvador & 30.6 & 58.8 & 52.5 & 57.5 & 70.8 & 79.3 & 82.3 & 81.0 \\
\hline Guatemala & 43.3 & 50.6 & 57.9 & 58.0 & 62.6 & 60.8 & 55.6 & 57.8 \\
\hline Honduras & 43.7 & 43.1 & 51.8 & 59.6 & 71.2 & 81.2 & 72.7 & 70.0 \\
\hline Nicaragua & $\ldots$ & 10.6 & 17.9 & 12.7 & 13.6 & 13.2 & 17.1 & 31.6 \\
\hline República Dominicana & $\ldots$ & $\ldots$ & 40.4 & 44.5 & 45.7 & $\ldots$ & $\ldots$ & $\ldots$ \\
\hline
\end{tabular}

Fuente: Departamento de Comercio de los Estados Unidos y base de datos, BADECEL, de la CEPAL.

a Las importaciones estadounidenses figuran en valores FAS (franco en el muelle), y las exportaciones de los países corresponden al valor FOB. Lo anterior no incluye el costo de los servicios portuarios, y ambos representan el valor bruto de la producción.

CUADRO 5

Centroamérica y República Dominicana: Exportaciones de la maquila como porcentaje de las exportaciones totales, 1990-1997

\begin{tabular}{|c|c|c|c|c|c|c|c|c|}
\hline & 1990 & 1991 & 1992 & 1993 & 1994 & 1995 & 1996 & 1997 \\
\hline Costa Rica & 21.6 & 20.7 & 23.6 & 26.9 & 23.5 & 23.1 & 23.4 & $\ldots$ \\
\hline El Salvador & 12.6 & 32.9 & 26.7 & 28.1 & 34.7 & 39.6 & 46.3 & 44.5 \\
\hline Guatemala & 22.8 & 27.5 & 32.5 & 34.1 & 34.8 & 32.4 & 31.4 & 32.9 \\
\hline Honduras & 28.0 & 28.4 & 35.5 & 45.1 & 55.8 & 64.1 & 60.7 & 61.1 \\
\hline Nicaragua & $\ldots$ & 2.3 & 4.9 & 5.6 & 6.1 & 5.8 & 8.3 & 17.2 \\
\hline República Dominicana & $\ldots$ & $\ldots$ & 36.2 & 40.4 & 41.6 & $\ldots$ & $\ldots$ & $\ldots$ \\
\hline
\end{tabular}

Fuente: Departamento de Comercio de los Estados Unidos y base de datos, BADECEL, de la CEPAL. 


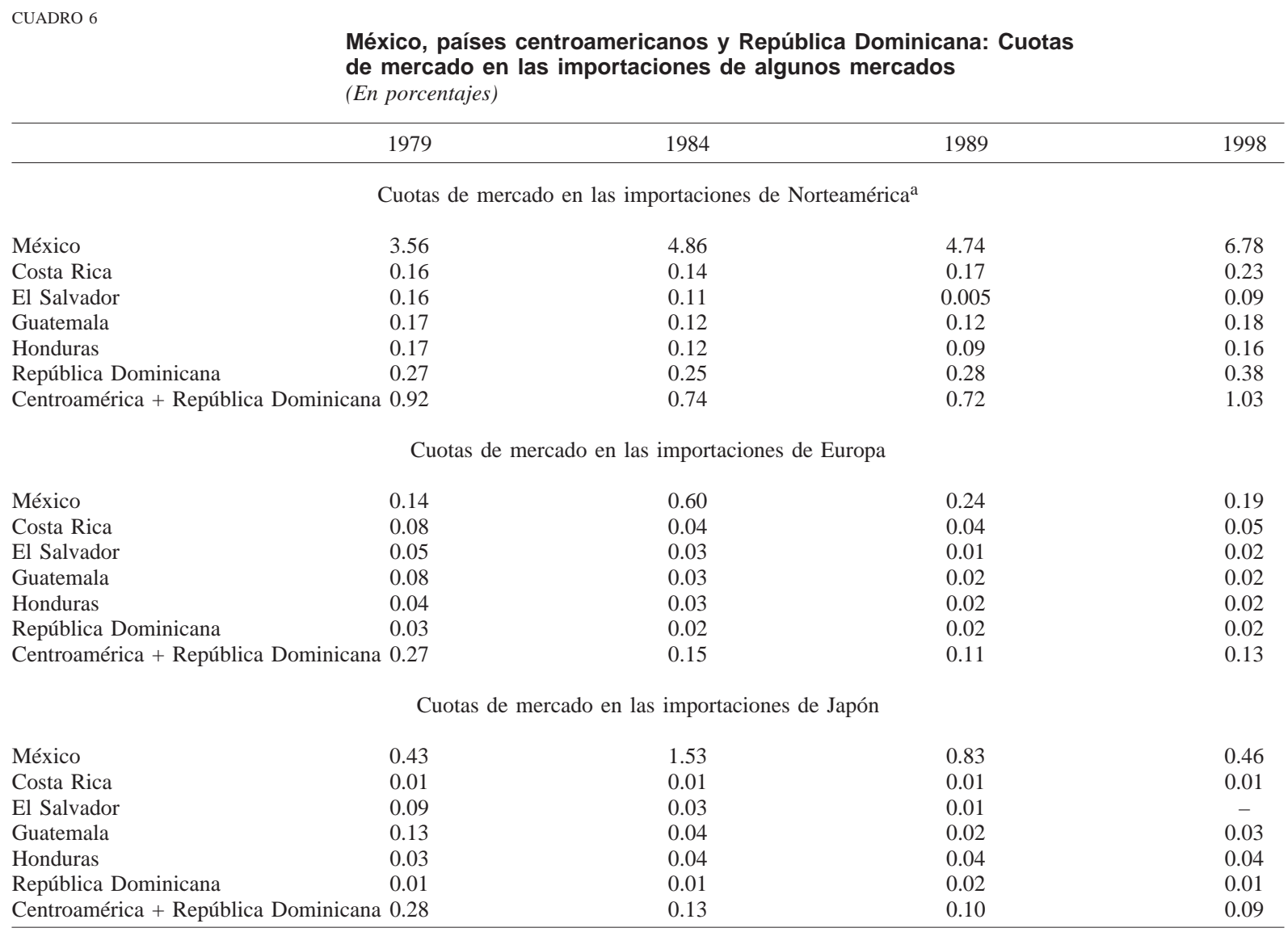

Fuente: Base de datos CANPLUS, de la CEPAL.

a Estados Unidos y Canadá.

exportaciones a los Estados Unidos registradas en los datos nacionales, ${ }^{5}$ puede obtenerse una aproximación de las exportaciones de la maquila de esos países. Las exportaciones de las maquiladoras de El Salvador y Honduras representan $70 \%$ a $80 \%$ de sus exportaciones totales a los Estados Unidos, porcentaje que ha aumentado notoriamente en los años noventa (cuadro 4); las exportaciones de la maquila de Costa Rica, Guatemala y la República Dominicana representan un $50 \%$. Expresadas como porcentaje de las exportaciones totales de estos países al mundo (cuadro 5), las exportaciones de las maquiladoras llegan al $61 \%$ en el caso de Honduras y casi al $50 \%$ en El Salvador y la República Dominicana. ${ }^{6}$

5 Según la base de datos BADECEL de la CEPAL.

6 Suele aceptarse que las exportaciones de la maquila incorporan menos materias primas locales que las demás exportaciones. En
Por último, el cuadro 6 muestra la participación de México, Centroamérica y la República Dominicana en el mercado norteamericano (Estados Unidos y Canadá), Europa y Japón. El aumento de las exportaciones de la maquila explica el notable incremento de la participación de estos países en el mercado norteamericano en los años noventa, mientras que su participación en los mercados europeos y japoneses casi no tuvo variación. Así, su notable desempeño exportador se basó sobre todo en sus exportaciones a los Estados Unidos y, en particular, en las exportaciones de las industrias maquiladoras a dicho mercado.

consecuencia, la contribución del valor agregado de las exportaciones de la maquila al valor agregado total de las exportaciones sería inferior a los porcentajes indicados en los cuadros 3,4 y 5 . 


\section{III}

\section{La industria maquiladora: origen y evolución}

Como ya se demostró, el aumento de la participación de mercado que lograron los países considerados obedece en gran medida a la industria maquiladora. ¿Pero qué es precisamente la maquila? El diccionario señala que es una palabra de origen árabe, que significa la porción de grano, harina o aceite que corresponde al molinero por la molienda. En términos económicos, sería una actividad en la que el propietario de la materia prima hace las veces de empresario que contrata al propietario del bien de capital y a su fuerza de trabajo para realizar un proceso productivo. El pago es un porcentaje fijo del producto elaborado.

El término maquila se asocia en el México moderno a un tipo de actividad económica que nació gracias al Programa de Industrialización Fronteriza. Este programa fue creado en 1965 para dar empleo a unos 200000 trabajadores mexicanos que tenían que regresar de los Estados Unidos debido al término del Programa Braceros que les había brindado empleo temporal en los Estados Unidos en épocas de escasez de mano de obra, en particular durante la Segunda Guerra Mundial y la guerra de Corea.

El Programa de Industrialización Fronteriza permitía la importación libre de derechos de bienes de capital e insumos, para la exportación del producto terminado. Tal vez recordaba a la antigua noción de maquila, puesto que México ofrece su territorio y fuerza de trabajo a un empresario extranjero que suministra insumos y regresa con el producto elaborado. En esencia, el programa pretendía atraer la inversión extranjera directa de origen estadounidense para establecer operaciones de ensamblado orientadas a la exportación a lo largo de la frontera septentrional. Como tal, se alejaba notoriamente de las políticas imperantes de sustitución de importaciones. En 1971 se modificó la legislación a fin de que las industrias maquiladoras pudieran establecerse en las áreas costeras y ciudades del interior de la República.

Las franquicias aduaneras que ofrecía México a la inversión extranjera directa para establecer operaciones de ensamble destinadas a la reexportación eran un complemento del trato arancelario que recibían en los Estados Unidos esos productos ensamblados. Desde 1930 existía en la nomenclatura arancelaria estadounidense la partida $\mathrm{N}^{\circ} 806.30$, en virtud de la cual ciertos productos de metal elaborados con materia prima de origen estadounidense podían reimportarse a los Estados Unidos, pagando el arancel correspondiente que sólo consideraba el valor agregado en el exterior. Esta disposición se dictó para facilitar las operaciones entre las empresas establecidas en Estados Unidos y Canadá. Más adelante se agregó la partida 807.00, aplicable a los bienes elaborados en el exterior con materiales de origen estadounidense, que facilitaba las operaciones de las empresas transnacionales estadounidenses en el exterior.

Centroamérica y la República Dominicana siguieron una estrategia distinta para atraer la inversión extranjera directa con el fin de establecer operaciones de ensamblado destinadas a la exportación, pero también trataron de aprovechar la partida arancelaria 807.00. En este caso, se crearon zonas francas industriales siguiendo el ejemplo de varios países del Asia sudoriental. En estas zonas francas, que eran parques industriales de propiedad estatal, se permitía también la importación libre de derechos de materias primas, insumos y bienes de capital para la reexportación del producto terminado. Algunos parques suministraban además instalaciones y servicios básicos para las operaciones de ensamblado. Con éxito variable, todos los países, salvo Costa Rica, establecieron esas zonas francas a comienzos de los años setenta. Costa Rica utilizó un régimen arancelario especial para favorecer el establecimiento de actividades de ensamble destinadas a la exportación.

La crisis de principios de los años ochenta provocó profundos cambios tanto en el entorno económico circundante de la industria maquiladora como en el marco jurídico en que operaba. Tras constituir la excepción en un marco de políticas proteccionistas, la industria de ensamblado orientada a la exportación pasó a ser la punta de lanza del cambio hacia un modelo de desarrollo inducido por las exportaciones. La gran prioridad política asignada a las exportaciones se tradujo primero en cambios del marco legal (recuadro 1). En 1984, Costa Rica aumentó los incentivos fiscales para las exportaciones fuera de la región centroamericana; perfeccionó la ley que regula la entrada temporal de bienes para la reexportación y permitió que el capital privado participara en la propiedad y administración de las zonas francas. Guatemala y Honduras 


\section{Recuadro 1}

Centroamérica: La eVolución del marco legal QUe Rige la industria MaQuiladora

Situación inicial

- La mayoría de las leyes sólo consideraban los programas especiales de fomento de las exportaciones.

- Sólo se permitía la propiedad y administración pública de las zonas francas.

- La instalación de zonas francas estaba restringida a ciertos lugares.

- Sólo se permitía la producción para la exportación.

- La inversión extranjera directa estaba restringida a ciertas actividades.

- Los beneficios de la maquila estaban restringidos a ciertas actividades.

Situación actual

- Hay tres regímenes vigentes: i) leyes sobre las zonas francas; ii) leyes sobre la entrada temporal y iii) sistemas de reintegro.

- La propiedad y administración de las zonas francas están abiertas al capital privado.

- Se tiende a permitir las zonas francas en todo el territorio nacional; en algunos países determinadas plantas pueden recibir la categoría de zona franca.

- Se tiende a permitir las ventas locales, después de pagar los derechos de importación.

- Hay liberalización y diversificación sectorial de la inversión extranjera directa.

- Los beneficios de la maquila están abiertos a todas las actividades orientadas a la exportación.

Fuente: Elaboración de los autores y de la ort (1996).

también promulgaron leyes ese mismo año relativas a la entrada temporal y las zonas francas industriales. En la República Dominicana, la liberalización del régimen cambiario reveló ser fundamental para atraer las operaciones de ensamblado. En muchos países esta legislación se revisó y mejoró con ulterioridad, con lo que el marco legal se volvió plenamente operativo a comienzos de los años noventa.

Otro hecho importante en el primer lustro de los años ochenta fue la creación de instituciones del sector privado para atraer la inversión extranjera directa. A título ilustrativo cabe citar la Coalición Costarricense de Iniciativas de Desarrollo (CINDE), la Gremial de Exportadores de Productos No Tradicionales (GEXPRONT) en Guatemala, la Fundación para las Inversiones y el Desarrollo Económico (FIDE) en Honduras, la Fundación Salvadoreña para el Desarrollo Económico y Social (FUSADES) y el Consejo para la Promoción de la Inversión (República Dominicana). En muchos casos, estas instituciones recibieron un apoyo considerable de la Agencia de los Estados Unidos para el Desarrollo Internacional, a veces por conducto de su Oficina Regional para Centroamérica y Panamá.

Los beneficios fiscales locales para las operaciones de ensamblado orientadas a la exportación y el establecimiento de instituciones de apoyo vinieron a complementar los importantes privilegios de acceso al mercado de los Estados Unidos otorgados por este país. La Ley de Recuperación Económica de la Cuenca del Caribe (CBERA) de 1983 (renovada en 1990) otorgó unilateralmente a algunos países acceso libre de derechos al mercado estadounidense para numerosos productos. Al principio se excluían las prendas de vestir, porque su acceso al mercado estadounidense se regía por restricciones de cuota bilaterales conforme al Acuerdo Multifibras. A partir de 1986 Estados Unidos negoció con los países acogidos a la CBERA programas especiales de acceso para facilitar las importaciones de prendas de vestir. Y lo que es más importante, se otorgaron "niveles de acceso garantizados" a países de Centroamérica y el Caribe que permitieron un acceso más libre al mercado estadounidense de las prendas de vestir elaboradas por esos países con telas estadounidenses. México, por su parte, negoció con los Estados Unidos en 1988 un régimen especial para que sus exportaciones de vestuario tuvieran un trato comparable al que se daba a las de los países favorecidos por la CBERA.

En el caso de México, las modificaciones legales más importantes fueron la autorización para que las industrias maquiladoras vendieran hasta 20\% (1983) y $50 \%$ (1989) de su producción en el mercado local. Ahora último, el Tratado de Libre Comercio de América del Norte (NAFTA) ha elevado gradualmente este 
porcentaje, de manera que para el 2001 se permitirá plenamente la venta local.

Naturalmente, la existencia misma de este tratado hace que los beneficios del programa maquilador mexicano sean menos relevantes para las exportaciones al mercado estadounidense, porque la mayoría de los aranceles pasaron inmediatamente a ser nulos y otros se redujeron gradualmente. Esto no significa que las operaciones de ensamble se hayan vuelto menos atractivas. En particular en la industria del vestuario, el NAFTA implicó el acceso libre de cuotas y aranceles de importación notoriamente menores para los productos exportados de origen mexicano. Además, se mejoraron los servicios de transporte, telecomunicaciones e inmigración para la gente de negocios. Sin embargo, las industrias ensambladoras pueden considerar otras opciones en vez del programa maquilador. El programa PITEX es otro plan de fomento de las exportaciones que se utiliza cada vez más para las operaciones de ensamble destinadas a la exportación (SECOFI, 1996). Fue creado para las empresas nacionales orientadas a la exportación y permite también la importación libre de derechos de materias primas y bienes de capital. Al contrario del programa maquiladora, no exime del impuesto a los activos. Asimismo, existe un mecanismo de reintegro, en virtud del cual las empresas pueden obtener la devolución de los impuestos a la importación pagados por insumos de bienes exportados.

Los beneficios fiscales en los países de la Cuenca del Caribe, incluido México, ${ }^{7}$ el establecimiento de instituciones de apoyo para atraer la inversión extranjera directa, el acceso privilegiado al mercado estadounidense y la presión competitiva sobre las empresas estadounidenses, ofrecieron el marco para un crecimiento explosivo de las operaciones de ensamble orientadas a la exportación.

En la literatura sobre México se ha señalado que el carácter de las operaciones de las maquiladoras varió con el tiempo. ${ }^{8}$ Los cambios se refieren a los sistemas organizacionales y la gestión de los recursos humanos, y a la importancia de la calidad y de los cambios tecnológicos. La llamada primera generación de plantas maquiladoras fueron plantas basadas en la intensificación de las operaciones manuales, más interesadas en el volumen que en la calidad. Su presencia predominó

\footnotetext{
7 Véase en Mortimore y Peres (1998) interesantes comentarios sobre la competencia en materia de políticas.

8 Véanse Carillo y Hualde (1997), Mertens y Palomares (1998), Wilson (1990) y Brown y Domínguez (1989).
}

hasta principios de los años ochenta. En cambio, las plantas de segunda generación debían ser capaces de responder con rapidez a los cambios de la demanda de productos con ciclos de vida breves y estándares de calidad más estrictos (Carillo, Mortimore y Estrada, 1998). Para ello se introdujeron nuevas tecnologías, así como nuevas formas de organización del proceso de producción y cambios en la gestión de recursos humanos; se automatizaron las líneas de producción y los trabajadores tuvieron que desempeñar múltiples funciones, y aumentó la proporción de ingenieros y técnicos. Este es el tipo de plantas maquiladoras que predomina hoy. Se ha detectado una tercera generación de maquiladoras en las que ingenieros mexicanos (con remuneración relativa menor) realizan actividades que hacen uso intensivo de conocimientos especializados de desarrollo y diseño de productos. Hasta ahora, estos casos son muy excepcionales.

A estas alturas parece claro que no hay una definición de industria maquiladora que sea precisa y válida a nivel internacional y, por lo tanto, no existe una fuente de datos uniforme sobre el crecimiento y las características de esta industria. México emplea su propia definición, y otorga la categoría de maquiladora a ciertas plantas y operaciones y recopila información estadística al respecto. En los países de Centroamérica y el Caribe hay información sobre empresas instaladas en las zonas francas industriales y empresas que pueden acogerse a los beneficios del fomento a las exportaciones y a los derechos de reintegro. Desde el punto de vista de los Estados Unidos, los datos acerca de las importaciones estadounidenses pueden arrojar luz sobre el desarrollo de la industria.

Las exportaciones de la maquila en México aumentaron casi $20 \%$ anualmente entre 1983 y $1997 .{ }^{9}$ Las tasas de crecimiento fueron especialmente acentuadas en $1987(26 \%)$ y 1998 (43\%). El empleo en la industria maquiladora subió en el mismo período a una tasa anual de 13\%: en 1997, había 2867 plantas que empleaban directamente a casi 940000 trabajadore (gráfico 2). En el último tiempo, el aumento del número de plantas y empleos ha sido particularmente pronunciado fuera de la zona fronteriza.

Entre 1988 y 1997 el empleo en el ensamblado de productos y componentes eléctricos y electrónicos se redujo de $40 \%$ a $34 \%$ del empleo total en la industria maquiladora. Los componentes de vehículos auto-

\footnotetext{
9 Calderón, Mortimore y Peres (1995) analizan el crecimiento de las exportaciones mexicanas.
} 
GRAFICO 2

México: Empleo en la maquila

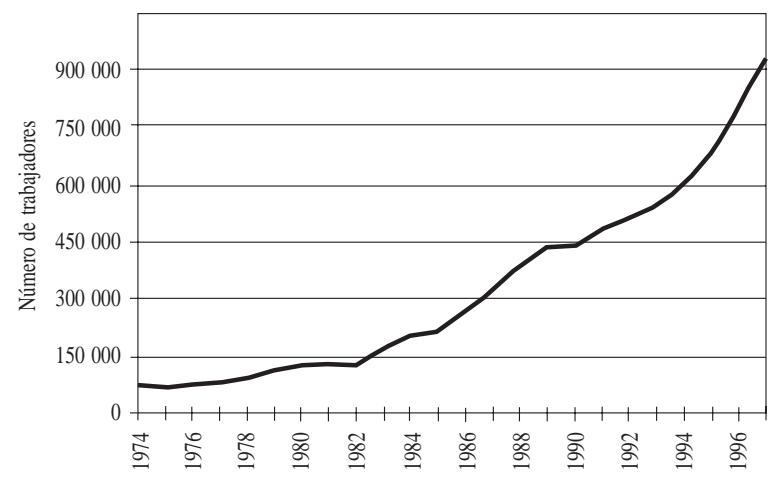

motores mantuvieron aproximadamente su contribución de $20 \%$ al empleo en la maquila, y las prendas de vestir aumentaron su participación de $9 \%$ en 1988 a $20 \%$ en 1997.

El valor agregado local de las exportaciones de la maquila disminuyó de $37 \%$ del valor bruto de la producción en 1974 a sólo $20 \%$ en 1997 . La adquisición local de insumos directos sigue siendo insignificante. Los salarios, que son el componente principal del valor agregado local, redujeron su participación en el valor bruto de la producción de $23 \%$ en 1974 a $10 \%$ en 1996 (gráfico 3). Esta tendencia revela el cambio a sectores y técnicas de producción con uso intensivo de capital, así como la caída de los salarios reales (Banco de México, varios años; INEGI, varios años).

A los países centroamericanos no les ha sido posible construir series cronológicas sobre las exportaciones y el empleo. En 1996, unas 800 plantas proporcionaron casi 250000 empleos directos (Gitli, 1997). A diferencia de las de México, la vasta mayoría de las plantas maquiladoras de Centroamérica están dedicadas a las prendas de vestir. Existen algunas empresas maquiladoras en el rubro eléctrico y electrónico, sobre todo en Costa Rica. Este sector recibió un impulso considerable con el establecimiento de una planta de ensamble de microprocesadores a comienzos de 1998.

El cuadro 7 indica el origen del capital, y resulta interesante observar la presencia de plantas de propiedad sudcoreana, en particular en Guatemala, y taiwanesa en Nicaragua. La presencia de capital asiático se explica principalmente por la existencia de restricciones de cuota para las exportaciones de vestuario a los Estados Unidos en sus países de origen. Asimismo, hay una presencia importante de capital local en la industria maquiladora, en particular en El Salvador, donde
GRAFICO 3
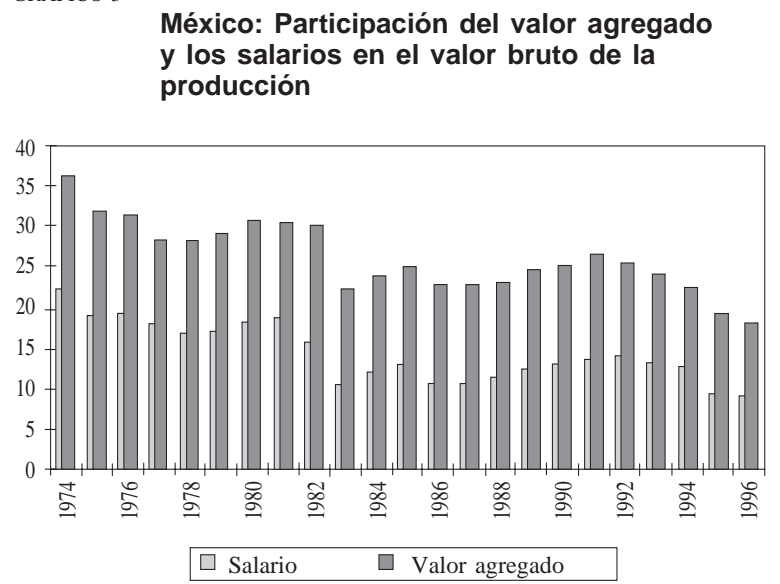

la ley permite otorgar la categoría de zona franca a determinadas plantas (Predios Fiscales). En Costa Rica, país donde las plantas maquiladoras se establecieron primero, hay un predominio manifiesto de empresas de propiedad estadounidense.

En la República Dominicana, las exportaciones y el empleo de las maquiladoras crecieron con rapidez a contar de 1985. En 1996 había 434 plantas en 36 zonas francas que exportaban por un valor total de 2800 millones de dólares y empleaban directamente a 165000 trabajadores (cuadro 8 y gráfico 4). Casi dos tercios del total de las exportaciones de la maquila consisten en prendas de vestir.

En suma, en los países examinados casi 4000 plantas denominadas "industrias maquiladoras" proporcionaron en 1996 cerca de 1500000 empleos directos.

Otra manera de aproximarse a la evolución de las industrias maquiladoras en los países mencionados es dar una mirada a las importaciones estadounidenses del principal grupo de productos involucrado, los de la industria del vestuario (cuadro 9). Hay que señalar que estos datos no coinciden necesariamente con lo que se considera industria maquiladora en los países de origen.

Mientras que en 1990 sólo 8\% de todas las importaciones estadounidenses de vestuario provenía de los países considerados, ocho años más tarde esta cifra había aumentado a más de $26 \%$. En dólares corrientes, las exportaciones de vestuario de estos países a los Estados Unidos se expandieron de 2100 millones de dólares a 12100 millones de dólares. Otro rasgo revelador del cuadro 9 son los aranceles. El arancel implícito se calcula dividiendo los derechos totales recaudados por el valor total de las importaciones. En 1990 este arancel mostraba un cuadro más bien uniforme que 
CUADRO 7

Centroamérica: Origen del capital, número de plantas y empleo

\begin{tabular}{|c|c|c|c|c|c|c|c|}
\hline \multirow[t]{2}{*}{ País } & \multicolumn{6}{|c|}{ Origen del capital } & \multirow[t]{2}{*}{ Empleo } \\
\hline & Plantas & Local & $\begin{array}{l}\text { Estados } \\
\text { Unidos }\end{array}$ & $\begin{array}{c}\text { República de } \\
\text { Corea }\end{array}$ & $\begin{array}{l}\text { Otros países } \\
\text { asiáticos }\end{array}$ & $\begin{array}{l}\text { Otros } \\
\text { países }\end{array}$ & \\
\hline Costa Rica & 189 & $39(21 \%)$ & $113(60 \%)$ & $4 \quad(2 \%)$ & $3(2 \%)$ & $30(16 \%)$ & 47972 \\
\hline El Salvador & 190 & $123(65 \%)$ & $20(11 \%)$ & $16(8 \%)$ & $12(6 \%)$ & $19(10 \%)$ & 42000 \\
\hline Guatemala & 220 & $95(43 \%)$ & $20(9 \%)$ & $96 \quad(8 \%)$ & $4 \quad(2 \%)$ & $5(2 \%)$ & 61800 \\
\hline Honduras & 174 & $56(32 \%)$ & $62(36 \%)$ & $37(21 \%)$ & $17(10 \%)$ & $2(2 \%)$ & 78583 \\
\hline Nicaragua & 19 & $3(16 \%)$ & $6(32 \%)$ & $3(16 \%)$ & $6(32 \%)$ & $1 \quad(5 \%)$ & 13000 \\
\hline Región & 792 & $316(40 \%)$ & $217(28 \%)$ & $156(20 \%)$ & $42(5 \%)$ & $57 \quad(7 \%)$ & 245355 \\
\hline
\end{tabular}

Fuente: Gitli (1997).

CUADRO 8

República Dominicana: Zonas francas industriales, 1990-1996

\begin{tabular}{|c|c|c|c|c|c|c|c|}
\hline & 1990 & 1991 & 1992 & 1993 & 1994 & 1995 & 1996 \\
\hline Exportaciones (en millones de dólares) & 1123.5 & 1415.8 & 1839.3 & 2165.1 & 2453.9 & 2700.1 & 2851.9 \\
\hline Valor agregado (en millones de dólares) & 351.7 & 448.1 & 575.7 & 677.7 & 768.1 & 845.1 & 892.6 \\
\hline Número de zonas francas industriales & 25 & 27 & 30 & 31 & 32 & 33 & 36 \\
\hline Número de plantas & 331 & 357 & 420 & 462 & 476 & 469 & 434 \\
\hline Empleo & 130045 & 135491 & 141056 & 164296 & 176311 & 165571 & 164639 \\
\hline
\end{tabular}

Fuente: Consejo Nacional de Zonas Francas.

GRAFICO 4

\section{República Dominicana: Zonas francas industriales}

A. Número de plantas, 1970-1996

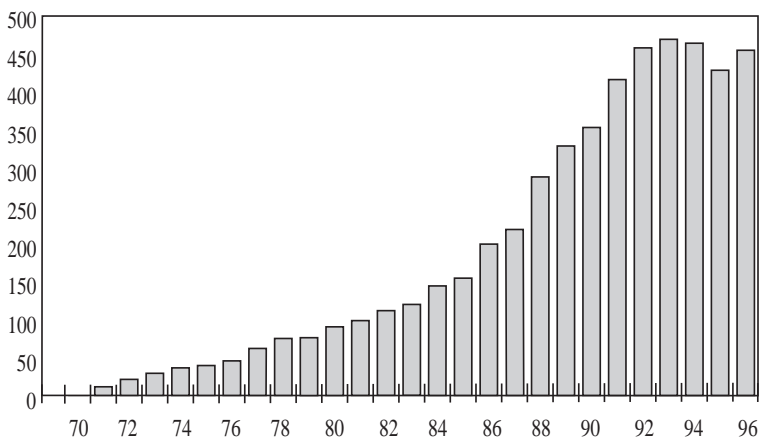

B. Exportaciones en millones de dólares, 1983-1996

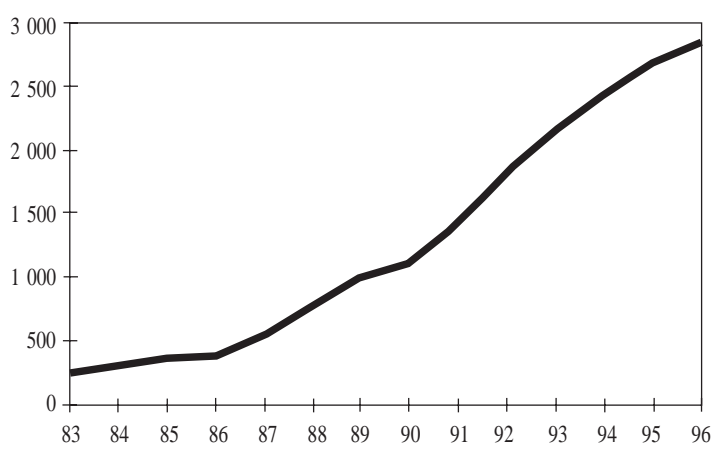

C. Empleo directo, 1970-1996 (número de personas ocupadas)

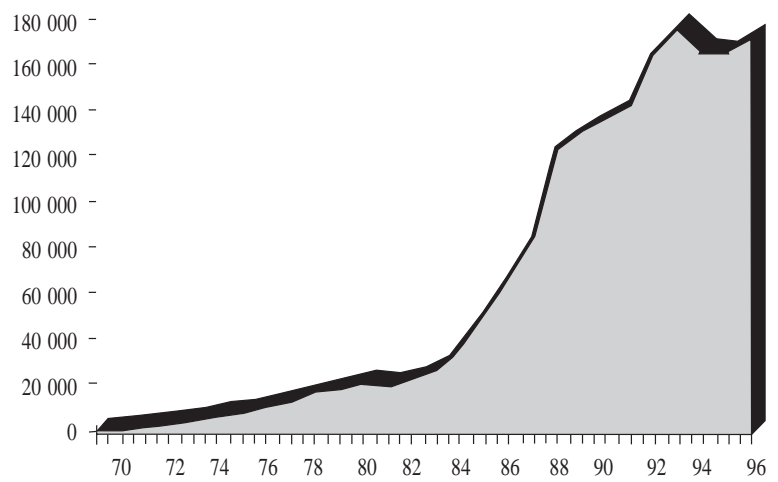

oscilaba entre 17 y $20 \%$. El NAFTA significó para las exportaciones mexicanas de vestuario la virtual eliminación de los aranceles, mientras que las disposiciones de acceso especial que benefician a Centroamérica y la República Dominicana redujeron los aranceles implícitos a una gama de 5 a 10\%. Las exportaciones de vestuario de los países sin acceso preferencial al mercado siguen pagando un arancel implícito bastante más elevado.

En el caso de la maquila mexicana, también las exportaciones de autopartes y maquinaria eléctrica y electrónica son sustanciales. Los automóviles y sus partes están registrados en la partida arancelaria 87, 
CUADRO 9

Estados Unidos: Importaciones

de prendas de vestir

(Capítulos arancelarios 61 y 62 totalizados)

\begin{tabular}{lccccc}
\hline País de origen & \multicolumn{2}{c}{$\begin{array}{c}\text { Participación de } \\
\text { mercado }\end{array}$} & & \multicolumn{2}{c}{$\begin{array}{c}\text { Arancel } \\
\text { implícito }\end{array}$} \\
\cline { 2 - 3 } & 1990 & 1997 & & 1990 & 1997 \\
\hline México & 1.79 & 11.75 & & 17.12 & 0.70 \\
Guatemala & 0.83 & 2.16 & & 19.41 & 9.85 \\
El Salvador & 0.24 & 2.36 & & 17.88 & 6.54 \\
Honduras & 0.49 & 3.78 & & 19.54 & 5.72 \\
Costa Rica & 1.64 & 1.89 & & 19.78 & 5.12 \\
República Dominicana & 2.98 & 4.90 & & 19.94 & 5.90 \\
\hline
\end{tabular}

Fuente: Datos tomados de: Departamento de Comercio de los Estados Unidos, US Imports of Merchandise (publicación en CD-ROM) y elaborados con el programa MAGIC de la CEPAL. donde México ha aumentado su cuota de mercado de $5 \%$ en 1990 a $13.4 \%$ en 1997 . Los aranceles implícitos cayeron de $2.8 \%$ a $0.6 \%$. La maquinaria eléctrica y electrónica y sus partes están registradas en la partida 84; la participación de mercado mexicana aumentó de $3.6 \%$ en 1990 a $7 \%$ en 1997 , mientras que los aranceles implícitos cayeron de 1.9 a $0.3 \%$.

El conjunto de estos hechos muestra claramente el desempeño impresionante de la industria maquiladora después de las modificaciones del marco legal, la creación de instituciones de apoyo y el ofrecimiento de condiciones de acceso al mercado que tuvieron lugar en los años ochenta y noventa. En la sección siguiente se analiza su impacto sobre el cambio técnico en los países examinados.

\section{IV}

\section{La maquila y el cambio tecnológico: resultados de un análisis del cuestionario}

La poderosa y creciente industria maquiladora de los países examinados, ¿genera algo más que empleo de baja remuneración y un ingreso de divisas exiguo? ¿Contribuye en algo a las capacidades productivas y tecnológicas locales? A fin de responder a estos interrogantes, se pidió a 75 gerentes de plantas maquiladoras que respondieran a un cuestionario centrado en los procesos de aprendizaje dentro de la planta y las relaciones entre la planta y las empresas e instituciones locales.

El cuestionario se compone de tres secciones. La primera explora en términos generales la estrategia de la planta maquiladora. La segunda examina la situación dentro de la planta respecto a la formación de capital humano y las actividades de investigación y desarrollo. La última investiga los vínculos entre la planta y su entorno, en términos de las relaciones con otras empresas, con los gobiernos y con las instituciones locales de educación y capacitación y de desarrollo tecnológico.

\section{Estrategias de la planta maquiladora}

Primero, en el cuestionario se pregunta por los motivos que avalan la existencia de la planta. Para una maquiladora perteneciente a una empresa estadouni- dense, el motivo principal es la reducción de costos utilizando mano de obra barata en los países mencionados. Para una empresa extranjera no estadounidense, el acceso preferencial al mercado de los Estados Unidos también suele ser el motivo principal, especialmente en rubros como el vestuario, donde la cuota por país de origen desempeña un papel importante. Para ambos tipos de empresa, el mercado estadounidense es prácticamente el único destino de la producción. Un empresario nacional puede tener otros motivos para involucrarse en operaciones de ensamblado pedidas por una empresa extranjera: por ejemplo, la rentabilidad debería ser más elevada o la inversión menos riesgosa que aquella en capacidad productiva para el mercado interno. $\mathrm{Al}$ respecto, las expectativas acerca de la demanda local, la evolución del tipo de cambio y los distintos tratos fiscales desempeñan un papel importante. Muchas empresas locales aceptan contratos de ensamblado para la exportación a fin de tener derecho a los beneficios fiscales que ofrece la legislación sobre la actividad maquiladora. En todo caso, la raison d'être económica principal es la abundancia de mano de obra barata que puede llevar a cabo operaciones con uso intensivo de trabajo.

No obstante, la principal estrategia competitiva de las plantas maquiladoras es la calidad del producto. 
Otro elemento que puede brindar a una planta una ventaja competitiva es la oportunidad. El desafío consiste en producir con el máximo de calidad en el mínimo de tiempo, utilizando la mano de obra relativamente barata que todas las demás plantas también utilizan. Esta estrategia competitiva calza claramente con la descripción de la industria maquiladora de segunda generación. Algo que ilustra esta búsqueda de calidad es el hecho de que un número importante de empresas entrevistadas contaba con la certificación ISO 9000, y casi todas las demás estaban en vías de solicitarla.

Por último, en la sección sobre estrategia del cuestionario se formula una pregunta acerca del grado de autonomía de la planta maquiladora (cuadro 10). Las respuestas dejaron bien claro qué clase de procesos de aprendizaje cabía esperar. Con la excepción de algunas respuestas sorprendentes, en general los gerentes de plantas maquiladoras carecen de poder de decisión sobre i) la adquisición de materias primas, ii) la selección de los productos finales, y iii) la comercialización. Si es que hay un departamento de adquisiciones, éste se dedica a la adquisición local de insumos que no intervienen directamente en el proceso de producción. Habitualmente las plantas maquiladoras carecen de departamento de ventas.

Los gerentes de una planta maquiladora pueden opinar sobre la selección de maquinaria y la estrategia financiera y de inversión. Suelen ser íntegramente responsables por la contratación y la capacitación del personal y la organización de la producción. Hay que decir que en las plantas de capital local los gerentes tienden a tener una gama más amplia de responsabilidades.

\section{Desarrollo de los recursos humanos}

Las características de los recursos humanos empleados son similares en casi todas las empresas visitadas.
Alrededor del $80 \%$ de los empleados tienen, como máximo, educación secundaria; casi no hay trabajadores que no tengan al menos educación primaria. Se tiende, especialmente en México, a contratar personas egresadas de la educación secundaria. La edad de más del $50 \%$ de los trabajadores oscila entre 18 y 24 años; otro tercio es menor de 35 años. En las plantas de vestuario, entre $60 \%$ y $90 \%$ de la fuerza de trabajo son mujeres.

Aunque parece muy alejada de lo que se entiende por "aportes a las capacidades tecnológicas locales", la capacitación que reciben los jóvenes y en especial las jóvenes en las plantas maquiladoras reviste suma importancia. Para la gran mayoría, que suele provenir del medio rural, es su primer contacto con el mundo formal, urbano e industrializado. Reciben capacitación sistemática respecto a la empresa y su tarea concreta, pero también sobre hábitos sociales, higiene, etc. Casi todas las empresas programan periódicamente cursos sobre control de calidad, eficiencia y reducción de costos y prevención de accidentes.

La capacitación en el empleo de los trabajadores es modesta dado que sólo se les exige que desempeñen tareas sencillas, para lo cual bastan unos pocos días de aprendizaje en el trabajo. La curva de aprendizaje es corta, sobre todo en la industria maquiladora, excepto en la del vestuario. Un trabajador puede alcanzar niveles de productividad normales en una semana. En algunas plantas de vestuario la curva de aprendizaje puede ser más prolongada.

Los supervisores y gerentes también reciben capacitación sistemática. Dos tendencias importantes quedaron claras durante las entrevistas: la proporción de trabajadores con educación técnica y académica avanzada va en aumento, con un número creciente de nacionales en su seno. La mayor complejidad de los procesos de producción explica la primera y la presión de los costos explica la segunda. El personal de inge-

CUADRO 10

México y Centroamérica: Participación en decisiones estratégicas (En porcentajes)

\begin{tabular}{|c|c|c|c|c|c|c|}
\hline & \multicolumn{3}{|c|}{ México } & \multicolumn{3}{|c|}{ Centroamérica } \\
\hline & Ninguna & Alguna & Plena & Ninguna & Alguna & Plena \\
\hline Adquisición de materia prima & 67 & 24 & 10 & 68 & 27 & 5 \\
\hline Selección de productos finales & 67 & 33 & - & 77 & 18 & 5 \\
\hline Selección de maquinaria & 24 & 19 & 57 & 9 & 27 & 64 \\
\hline Organización de la producción & - & 24 & 76 & 5 & 9 & 86 \\
\hline Capacitación y contratación & - & 10 & 90 & - & 14 & 86 \\
\hline Ventas y comercialización & 52 & 24 & 24 & 59 & 27 & 14 \\
\hline Inversión y financiamiento & 29 & 43 & 29 & 9 & 18 & 73 \\
\hline
\end{tabular}

Fuente: Elaboración propia. 
nieros y técnicos especializados locales recibe cursos sobre técnicas de capacitación, control de calidad, trabajo en equipo y gestión de recursos humanos. Está en contacto frecuente con ingenieros extranjeros que visitan la planta y prestan asistencia técnica, supervisión y capacitación. Además, los ingenieros locales tienen que visitar con frecuencia las sedes y las plantas de la empresa matriz en otros países, para aprender in situ las técnicas de producción. Este tipo de interacción parece ser más frecuente en las filiales ciento por ciento de empresas extranjeras que en las plantas maquiladoras de capital nacional. El personal administrativo recibe capacitación en planificación estratégica, liderazgo, satisfacción del cliente, reglamentación fiscal y laboral, y demás cursos de autoperfeccionamiento, tales como "los siete hábitos de la gente altamente eficiente".

Por último, cabe formular un comentario sobre el aporte de las industrias maquiladoras a la formación de empresarios, que es tal vez el recurso humano que más falta en los países en desarrollo. El capital local participa de manera significativa en las industrias maquiladoras. En consecuencia, hay un grupo de empresarios nacionales que posee tanto plantas para la venta en el país como plantas de ensamblado para la exportación. La relación con el cliente extranjero les permite mantenerse informados sobre las innovaciones en materia de productos y procesos y recibir asistencia técnica. El conocimiento así adquirido puede transferirse a la planta destinada a la producción nacional, generando importantes aumentos de la productividad. La automatización de los procesos productivos y la introducción de técnicas organizacionales modernas se mencionan con frecuencia entre los beneficios así recibidos.

No obstante, la maquila no parece ser una activi- dad idónea para fortalecer las habilidades empresariales. Sólo excepcionalmente los gerentes y el personal técnico local de las plantas maquiladoras han logrado establecer sus propias empresas. El problema parece ser la ausencia de un grupo de empresarios locales suficientemente agresivo e innovador, y la falta de apoyo financiero y tecnológico. Asimismo, los estrictos requisitos de las empresas transnacionales respecto a sus proveedores constituyen una barrera para ingresar a la industria.

Los resultados del estudio basado en el cuestionario demuestran que la contribución de la maquila al aprendizaje tecnológico radica en particular en la organización de la producción (cuadro 11). La mayoría de las personas entrevistadas confirman que en sus plantas se usan técnicas organizacionales modernas como la producción flexible, el control total de la calidad, la producción justo a tiempo y el perfeccionamiento continuo. No cabe duda de que la utilización de estas técnicas se halla más difundida en las plantas maquiladoras que en otras empresas nacionales; por lo demás, no se trata de meras imitaciones, pues la mayoría de los gerentes confirmaron la necesidad de adaptar las técnicas organizacionales a las condiciones e idiosincrasia de la fuerza de trabajo local.

En todos los países considerados se presiona a las plantas maquiladoras para que entreguen a tiempo grandes volúmenes de un producto de óptima calidad, manteniendo los costos de producción controlados. Esta presión genera la búsqueda continua del método más eficiente para organizar la producción. Constantemente se introducen nuevos sistemas de gestión y organización, y casi todas las plantas maquiladoras emplean equipos de producción, programas de control de calidad, manuales y normas de operación y programas de sugerencias de los trabajadores.

CUADRO 11

México y Centroamérica: Métodos y programas para organizar la
producción que aplican las maquiladoras entrevistadas

(Porcentaje de respuestas afirmativas)

\begin{tabular}{lcc}
\hline & México & Centroamérica \\
\hline Control total de la calidad & 90 & 64 \\
Producción justo a tiempo & 65 & 68 \\
Mejoramiento continuo & 80 & 55 \\
Trabajo en equipo & 75 & 77 \\
Manuales, procedimientos y normas internas & 90 & 82 \\
Programas de sugerencias de los trabajadores & 50 & 77 \\
Intercambio de información técnica y económica con los trabajadores & 65 & 72 \\
Programas para aumentar la seguridad en el empleo & 85 & 91 \\
Programas ergonómicos & 55 & 64 \\
\hline
\end{tabular}

Fuente: Elaboración propia. 


\section{Evolución tecnológica de los procesos de pro- ducción en las plantas maquiladoras}

También es importante el aporte que hace la maquila al conocimiento de los procesos de producción. Las maquiladoras de segunda generación utilizan tecnología de vanguardia para satisfacer los estándares de calidad de los clientes. El personal técnico y de supervisión recibe capacitación constante para utilizar la maquinaria y mantenerse a la vanguardia del avance tecnológico. Las plantas maquiladoras prácticamente no hacen contribución alguna a la introducción y desarrollo de nuevos productos. Este último sigue realizándose en las sedes de las empresas matrices.

En las plantas visitadas de los seis países considerados se observa un interesante proceso de evolución de las tareas realizadas. En muchos casos, una planta de ensamble parte sólo con un número limitado de operaciones sencillas. Una vez que satisface los estándares del cliente, se le transfieren otras partes más complejas del proceso de producción y, a veces, hasta el proceso íntegro. Después de algunos años, la maquiladora puede incluso retroalimentar a la empresa matriz y sugerir cambios en el proceso de producción. En algunos casos se ha observado que todo el proceso de ensayo y adaptación de una nueva línea de producción se realiza en la planta maquiladora. Parece haber dos tipos de razones que explican esta tendencia. Primero, están las razones relacionadas con los procesos de aprendizaje dentro de la planta: a medida que aumenta la calidad y eficiencia de la mano de obra, crece la confianza de los clientes estadounidenses en las capacidades de la maquiladora y le encomiendan una gama más amplia de tareas. Segundo, hay razones externas a la planta: las ventajas competitivas de contar con procesos de fabricación integrales e incluso el diseño de productos y procesos en un solo lugar. La necesidad de responder con agilidad a las variaciones de la demanda, y los efectos positivos que surgen de la interacción entre los departamentos de productos y diseño, generan una tendencia hacia la concentración geográfica de las tareas.

En las plantas maquiladoras de Centroamérica y la República Dominicana, particularmente las de la confección, esta evolución se traduce en una mayor integración de los procesos productivos y la introducción de maquinaria más sofisticada. Cabe observar una doble tendencia hacia la producción integral, llamada de paquete completo, ${ }^{10}$ y la automatización. Los téc-

\footnotetext{
${ }^{10}$ En la producción de paquete completo la maquiladora adquiere
} la tela y los accesorios, y corta, cose, termina y embala el producto. nicos e ingenieros entrevistados subrayaron la importancia de estar en contacto con el proceso completo de producción para obtener un mejor aprendizaje (Vicens, Martínez y Mortimore, 1998).

En México se observó que cuatro plantas cuentan con departamentos de diseño de productos, dotados de ingenieros extranjeros y nacionales. Estos departamentos contribuyen con el diseño de partes menores del producto final, que no suelen ser las más exigentes desde el punto de vista tecnológico. En dos plantas, una productora de televisores y otra de órganos eléctricos, el diseño de la estructura externa se efectúa localmente. En otra de sistemas de aire acondicionado, los tubos y conectores se diseñan en el país. Sólo en la fábrica de muebles todo el diseño se hace en la propia planta.

Aunque es obvio que estos cuatro casos son excepcionales, todas las plantas visitadas tenían departamentos de control de calidad con algunas capacidades tecnológicas. En el sector vestuario el diseño de productos se efectúa más próximo al lugar de la venta final, para estar en contacto directo con los compradores finales. La casa matriz extranjera envía a la maquiladora los modelos y las especificaciones exactas del producto. No obstante, en todos los países se observaron varios casos de plantas que trabajan con prototipos y realizan ensayos. Ocurre que del extranjero se reciben especificaciones de productos y manuales de operación que se ensayan en la planta, y luego se elaboran informes con recomendaciones sobre especificaciones y el diseño de productos e insumos para discutirlos con la empresa matriz.

En México también se observaron actividades para mejorar progresivamente las especificaciones y el diseño de los productos. Más de 50\% de las plantas visitadas declararon haber contribuido, aunque a veces con detalles menores, a las características del producto, mediante, por ejemplo, sugerencias de utilizar materias primas diferentes, recomendaciones que llevaron a reducir el uso de insumos, modificaciones que permitieron un ensamblado más fácil y un mejor funcionamiento del producto final, y cambios en la presentación del producto. En todos estos mejoramientos progresivos, la decisión definitiva no la toman los ingenieros mexicanos o extranjeros de la planta. En todos los casos hay que informar de las sugerencias a los

El cliente se concentra en la comercialización y distribución. En otro tipo de contratos, la maquiladora sólo corta, cose, termina y embala el producto, mientras que el cliente suministra la tela y los accesorios. 
centros de investigación y desarrollo de la sede, donde se toma la decisión definitiva.

En general, en la planta maquiladora no se realizan actividades de investigación y desarrollo relativas a la maquinaria. Es la empresa matriz extranjera la que suele seleccionar la maquinaria y son los ingenieros extranjeros los que realizan o al menos supervisan la instalación de líneas de producción. Sin embargo, los ingenieros nacionales pueden participar en la instalación de éstas y aprender así el oficio. En algunos casos, las líneas de producción ulteriores son instaladas por ingenieros nacionales sin la asistencia técnica de la empresa matriz.

En la mayoría de los casos el personal local realiza algunas operaciones de mantención, pero si surge un problema grave, sobre todo con las máquinas más complejas, los especialistas tienen que venir del exterior o hay que enviar partes de máquinas al proveedor. Cuando la planta maquiladora introduce "innovaciones" en la maquinaria, se trata de componentes periféricos que aceleran el proceso de producción. Asimismo, los ingenieros locales han efectuado pequeñas mejoras ergonómicas para ajustar la maquinaria al tamaño y las proporciones de los trabajadores mexicanos y centroamericanos, y se han diseñado y fabricado algunas herramientas auxiliares.

\section{Difusión del aprendizaje tecnológico fuera de la planta maquiladora}

Cabe recordar que la existencia de vínculos débiles entre la planta maquiladora y las empresas locales implica que no hay procesos directos de transferencia de capacidades tecnológicas y conocimientos técnicos. Si es que hay alguna difusión de los procesos de aprendizaje, ésta se hace mediante la capacitación de la fuerza de trabajo, la que puede mejorar las capacidades humanas en general.

A lo largo de la frontera norte de México, en Costa Rica y hasta cierto punto en la República Dominicana y Honduras, existen relaciones formales entre las plantas maquiladoras y sus asociaciones y las escuelas e institutos de formación profesional. La idea es mejorar la preparación de la mano de obra antes de que ingrese a la maquiladora. En el norte de México, es evidente que la CONALEP, la CECATI, la CETIS, las universidades estaduales y los diferentes campus del Ins- tituto Tecnológico y de Estudios Superiores de Monterrey, son ejemplos de institutos educacionales que mantienen una estrecha relación con la industria maquiladora, y que definen en parte su currículo conforme a las necesidades de dichas plantas. En particular, existe en Ciudad Juárez un activo "comité de enlace" en que los representantes de los centros educacionales y de las plantas maquiladoras analizan las necesidades de capacitación de la futura fuerza de trabajo. En Costa Rica, la mayoría de las plantas visitadas reconocen la importancia de su relación con el Instituto Tecnológico de Costa Rica y el Instituto de Formación Vocacional. Naturalmente que la instalación de una planta del tamaño de INTEL en Costa Rica, con su política de contratar sólo personas que además de enseñanza secundaria posean un título de técnico, hablen inglés y operen el programa Microsoft Office, ha remecido todo el sistema educativo. La empresa tiene ideas explícitas sobre la política educacional en Costa Rica y trabaja en estrecha colaboración con las autoridades nacionales para mejorar la calidad de todo el sistema. La mayoría de los colegios e institutos de capacitación han introducido cambios en sus programas a fin de dotar de recursos humanos a la incipiente industria maquiladora microelectrónica.

Las plantas maquiladoras de propiedad nacional merecen un comentario especial. Las empresas locales que realizan operaciones de montaje para clientes extranjeros no suelen destinar toda su capacidad de producción a estas operaciones, y mantienen líneas de producción para atender la demanda interna. Por lo tanto, puede haber transferencia de conocimientos entre la planta maquiladora y las demás actividades de producción de esta empresa local. La transferencia efectiva de tecnología por este conducto depende del tipo de relación con el cliente extranjero, las características del producto ensamblado y la similitud entre la línea de maquila y las demás líneas de producción.

Según varios gerentes entrevistados, las capacidades tecnológicas y productivas de las empresas locales han mejorado gracias a las operaciones de ensamble y la interacción con especialistas extranjeros de las empresas transnacionales. Se han introducido nuevos productos, nuevas técnicas de producción y nuevas formas de organización de la empresa y del proceso de producción. 


\section{V}

\section{Conclusiones}

En este artículo se plantea el interrogante central de si las industrias maquiladoras contribuyen en algo al desarrollo tecnológico local. La respuesta ha de ser afirmativa. La industria maquiladora emplea técnicas de producción cercanas a la práctica óptima en el plano internacional, algo que sólo puede decirse de un reducido número de plantas manufactureras locales. Además, las maquiladoras contribuyen a la formación de recursos humanos e introducen conceptos modernos de organización y gestión.

Dicho esto, no es menos cierto que las actividades de la maquila son sobre todo intensivas en el uso de mano de obra poco calificada, que existe en abundancia en los países de la cuenca del Caribe y en México. Por lo tanto, parece inadecuado sugerir que las actividades maquiladoras podrían ofrecer el tipo de inserción internacional que permitiría que esos países alcanzaran una senda de crecimiento sustentable con equidad. El alto contenido de importaciones y el escaso valor agregado de la maquila local limitan su efecto multiplicador sobre la demanda, de modo que su contribución al crecimiento es menor de lo que cabría esperar del volumen de la actividad. Si las industrias maquiladoras actuales se multiplicaran y dominaran por completo la estructura de producción y exportación, estos países se especializarían en la oferta de mano de obra barata y su crecimiento dependería exclusivamente de la competitividad en función de los costos de este factor de producción, lo que no parece compatible con una estrategia de largo plazo de crecimiento con equidad. En el corto plazo, dada la abundancia de oferta de mano de obra poco calificada, es indudable que las industrias de la maquila sí contribuyen positivamente a la equidad, por su capacidad impresionante de generar empleo, en particular para los desempleados o subempleados pobres de hoy.

La maquila en su forma actual no parece ser el motor del desarrollo sustentable con equidad, aunque su contribución es sin duda positiva. El camino a seguir sería entonces el de transformar la industria de la maquila en una actividad que no sólo base su competitividad en los salarios bajos y en las condiciones de acceso privilegiado al mercado, sino también en aumentos de la productividad y del contenido de valor agregado. Por otra parte, la maquila podría sig- nificar la transferencia de tecnología a la economía en su conjunto. La difusión de conocimientos adquiridos por la industria maquiladora a otros sectores de la economía es todavía escasa, debido al fuerte dualismo entre la maquila y la producción interna y también a la poca capacidad de absorción de las economías nacionales.

Además, hay varios obstáculos externos que impiden una mayor contribución de la actividad maquiladora al desarrollo sustentable con equidad. En primer lugar, las empresas transnacionales siguen manteniendo la política de transferir tecnologías "llave en mano", sin transferir actividades de investigación y desarrollo tecnológico. En segundo lugar, las empresas transnacionales no estimulan la compra de insumos locales, ya sea porque están integradas verticalmente o porque han establecido una red de proveedores a la que es difícil el ingreso de las empresas locales, porque el proceso de certificación de la calidad de proveedor exige tiempo, dinero y capacidades tecnológicas que ellas no tienen.

El cambio desde la maquila dedicada a la confección a la llamada maquila "de alta tecnología", proceso que está en curso en Costa Rica, no parece ser un elemento suficiente para que la actividad maquiladora pase a ser una fuente importante de progreso tecnológico. Al respecto, el análisis del cuestionario reveló claramente las limitaciones de la maquila microelectrónica. Primero, predominan las tareas de ensamble manual, así como el control manual de la maquinaria y la inspección visual de la calidad. Segundo, la tecnología se transfiere llave en mano, sin investigación ni desarrollo local. Tercero, en la economía nacional no hay empresas microelectrónicas que puedan absorber personal con conocimientos adquiridos por intermedio de la maquila. Cuarto, la falta de contenido local limita la difusión de conocimientos. Por último, el ritmo acelerado del desarrollo tecnológico en la microelectrónica tiende a anular las posibilidades de que los gerentes locales se conviertan en agentes de la "endogenización" de la tecnología.

En caso de que lo expuesto represente adecuadamente lo que las industrias maquiladoras contribuyen al progreso tecnológico en los países considerados, quedan aún tres preguntas que esperan respuesta. Pri- 
mero, si la industria maquiladora va a evolucionar de una actividad que hace uso intensivo de mano de obra poco calificada y mal remunerada a otras actividades que hacen uso intensivo de conocimientos y capacidades productivas; segundo, si el progreso tecnológico de las industrias maquiladoras va a difundirse en la economía nacional; y tercero, de qué manera las políticas públicas pueden contribuir a obtener respuestas afirmativas a las dos primeras preguntas.

Respecto a la evolución de la industria maquiladora, el contraste entre los casos nacionales aporta algunas respuestas. La maquila en México existe hace más de treinta años y su estructura de producción difiere notablemente de la maquila en Centroamérica y la República Dominicana. En México, la mayoría de las plantas pertenecen a sectores de alta tecnología como autopartes, artefactos eléctricos y artículos microelectrónicos. Si bien es cierto que en México sólo se realizan las partes más intensivas en trabajo de los procesos de producción que hacen uso más intensivo de trabajo, no es menos cierto que estas empresas contratan a personal cada vez más calificado. Rara vez emplean a trabajadores que sólo tienen educación primaria, y la proporción de técnicos e ingenieros locales va en aumento. Un patrón similar se observa en Costa Rica con el ingreso de plantas importantes al sector de la microelectrónica.

La presión que ejerce la maquila sobre el mercado laboral local aumenta los salarios reales. Esto exige, a su vez, que la industria maquiladora evolucione hacia actividades con un mayor valor agregado que permita pagar mayores salarios. No obstante, esta evolución será imposible sin el apoyo efectivo de sistemas nacionales de formación de recursos humanos y de instituciones que respalden el desarrollo tecnológico.

En suma, la evolución de la industria maquiladora hacia actividades que exigen fuerzas de trabajo más calificadas es posible, como lo demuestra el caso mexicano. Será inevitable cuando las presiones sobre el mercado laboral eleven los salarios reales, como sucede en Costa Rica. Pero no ocurrirá en forma automática y menos todavía en países que carecen de instituciones de apoyo para ello.

En cuanto a la segunda pregunta, la difusión del cambio tecnológico en la economía nacional se ve limitada por tres circunstancias. La primera es que el progreso técnico de la industria maquiladora tiene de por sí carácter limitado; la segunda es que los vínculos entre la maquila y la economía nacional son débiles; y la tercera, que la capacidad de absorción de la economía nacional es frágil.
Con relación al tema de la formación de recursos humanos, el interrogante principal se refiere a la utilidad de los conocimientos adquiridos en otras empresas y otras funciones, lo que sería un indicador de la posibilidad de que las capacidades pudieran utilizarse en otras actividades económicas. Aquí convendría establecer una distinción entre la maquila de la confección y otros tipos de maquila. En el sector de la confección, las aptitudes adquiridas por la fuerza de trabajo se emplean generalmente en las actividades nacionales y también en las fábricas de vestuario locales. Hay ciertos indicios de que la gente que ha aprendido técnicas de producción en las plantas maquiladoras instala pequeños talleres de sastrería para el mercado interno. En otras actividades de la maquila, el tipo de aprendizaje parece ser tan específico que su utilidad fuera de la planta maquiladora es muy escasa. En general, las empresas maquiladoras tienden a preferir la contratación de gente sin experiencia previa debido a su mejor disposición a aprender habilidades específicas relacionadas con el trabajo que requiere la planta.

En cambio, es más probable que el aprendizaje de los técnicos e ingenieros locales sea útil para otras empresas, sean o no de la maquila. La demanda de esos recursos humanos es tan grande, que con frecuencia los técnicos y supervisores dejan las plantas maquiladoras ante la perspectiva de mejores salarios y más beneficios secundarios.

Parte del conocimiento relativo a los procesos de producción puede transferirse a otras actividades económicas, incluso fuera de la industria maquiladora, especialmente en el sector vestuario. La difusión de conocimientos no parece ser de tal magnitud como para incidir en el nivel de productividad de la industria manufacturera en su conjunto. Esto se explica porque, salvo la industria de vestuario, los demás sectores en que participa la industria maquiladora no están representados en la economía nacional. También podría influir el menor nivel de exigencia de calidad en la industria nacional que en la maquiladora. Por último, las empresas nacionales tendrían menos posibilidades financieras de adquirir maquinaria de vanguardia y de tener el mismo acceso a la asistencia técnica.

Otra circunstancia que limita la difusión del cambio técnico en la economía nacional es la escasez de vínculos entre la industria maquiladora y las empresas e instituciones locales. Debido a la naturaleza de las operaciones de ensamble y al marco legal en que se desenvuelven, la industria maquiladora importa prácticamente toda la materia prima e insumos utilizados 
en el proceso de producción y, por lo tanto, no alienta el surgimiento de proveedores locales. Dado que las plantas exportan casi todo lo que producen, tampoco existe una competencia directa con las plantas locales en el mercado interno, algo que obligaría a las empresas locales a ponerse al día con el estándar tecnológico de la industria maquiladora. Existen algunos vínculos con instituciones locales de formación de recursos humanos, pero prácticamente no hay relaciones con instituciones de investigación y desarrollo tecnológico.

La última de las circunstancias mencionadas, la poca capacidad de las empresas nacionales para absorber el progreso tecnológico generado en la industria maquiladora, exige un análisis que escapa al ámbito del presente artículo. Cabría señalar que hay una diferencia entre México y Costa Rica, por una parte, y los países centroamericanos y la República Dominicana, por la otra. El nivel de desarrollo de los recursos humanos y de las instituciones locales que apoyan el progreso tecnológico es mucho mayor en los dos primeros países.

Esto nos lleva a responder la tercera pregunta, relativa a las políticas para promover la evolución de las plantas maquiladoras hacia actividades que hagan uso más intensivo de conocimientos y fomentar los vínculos entre las plantas maquiladoras y los proveedores locales. Para ello, creemos que es esencial considerar la maquila como parte integral de las estrategias para mejorar el desarrollo productivo. Antes se consideraba que la maquila tomaba parte exclusivamente en las políticas de empleo. Más tarde también se la vió como generadora de divisas. Hasta ahora no ha sido tomada en cuenta como estrategia para desarrollar las capacidades productivas locales.

Esto explica tal vez la dualidad existente entre la especialización productiva en las industrias maquiladoras y en el resto de la economía. El elemento de fomento de los enlaces productivos simplemente no se estimó relevante cuando se idearon los planes respectivos. Pero la industria maquiladora de hoy es un fenómeno de tal magnitud que indudablemente forma parte de la estructura de producción de los países mencionados.

Considerar que la maquila es una parte integral de una estrategia de desarrollo productivo no implica incrementar la injerencia gubernamental a un nivel que impida el crecimiento de la industria. Es evidente que en la zona fronteriza mexicana los gobiernos locales y las organizaciones de maquiladoras interactúan en beneficio mutuo. En todo caso, las estrategias actuales de desarrollo productivo en América Latina no discriminan de antemano entre los distintos sectores productivos. Se concentran en el mejoramiento de los recursos humanos, el fortalecimiento de las instituciones que apoyan el desarrollo tecnológico, la inversión en infraestructura y los programas de apoyo financiero. Respecto a estas esferas de política, deberían tomarse en cuenta los intereses de la industria maquiladora tal como se toman hoy en cuenta los de otros sectores productivos. Sólo mediante el fortalecimiento general de las capacidades productivas y tecnológicas locales puede la industria maquiladora transitar con éxito hacia actividades de mayor valor agregado local, y pueden fortalecerse los vínculos entre la maquila y la economía nacional e incrementarse la capacidad de absorción de la economía nacional.

Hay un aspecto particular que merece especial atención, y es el régimen tributario para la industria maquiladora y las empresas locales. La esencia de los programas de la maquila y de las zonas francas industriales fue la exención de los impuestos a la importación. Actualmente, también las empresas exportadoras nacionales pueden recibir esos beneficios mediante los planes de reintegro, que operan más o menos en las mismas condiciones. No obstante, los esfuerzos locales por atraer la inversión extranjera directa han incluido también la concesión de la exoneración temporal de otros impuestos a la renta de las sociedades, en especial el impuesto a las utilidades (Centroamérica) y a los activos (en México). Actualmente, se tiende a permitir que la industria maquiladora venda también en el mercado local, previo pago de los impuestos de importación, los que son cada vez más desdeñables. La industria maquiladora conserva, no obstante, el privilegio de no pagar otros impuestos a la renta de las sociedades. Este régimen tributario distinto alienta a la empresa nacional a establecerse en las zonas francas o a solicitar que se le otorgue la categoría de maquiladora. Para que la empresa maquiladora fuese considerada igual a las demás industrias manufactureras, habría que eliminar estos regímenes tributarios distintos.

(Traducido del inglés) 


\section{Bibliografía}

Banco de México (varios años): Indicadores económicos, sector externo, balanza comercial, México, D.F.

Brown, F. y L. Domínguez (1989): Nuevas tecnologías en la industria maquiladora de exportación, Comercio exterior, vol. 39, $\mathrm{N}^{\circ}$ 3, México, D.F., Banco Nacional de Comercio Exterior, S.N.C.

Calderón, A., M. Mortimore y W. Peres (1995): Mexico's Incorporation into the New Industrial Order: Foreign Investment as a Source of International Competitiveness, serie Desarrollo productivo, $N^{\circ} 21$, LC/G.1864, Santiago de Chile, Comisión Económica para América Latina y el Caribe (CEPAL).

Carrillo, J. y A. Hualde (1997): Maquiladoras de tercera generación: el caso de Delphi-General Motors, México, D.F., El Colegio de la Frontera Norte.

Carrillo, J., M. Mortimore y J. A. Estrada (1998): El impacto de las empresas transnacionales en la reestructuración industrial de México. El caso de las industrias de partes para vehículos y de televisores, Desarrollo productivo, $\mathrm{N}^{\circ}$ 50, LC/G.1994, Santiago de Chile, CEPAL.

CEPAL (1990): Transformación productiva con equidad, LC/G.1601-P, Santiago de Chile. Publicación de la Naciones Unidas, $\mathrm{N}^{\circ}$ de venta S.90.II.G.6.

(1996): México: la industria maquiladora, Estudios e informes de la CEPAL, $\mathrm{N}^{\circ}$ 95, Santiago de Chile.

(1998): Centroamérica, México y República Dominicana: maquila y transformación productiva, Santiago de Chile.

Fajnzylber, F. (1991): Inserción internacional e innovación institucional, Revista de la CEPAL, No 44, LC/G.1667-P, Santiago de Chile, CEPAL.

Gitli, E. (1997): La industria de la maquila en Centroamérica, San José, Costa Rica, Organización Internacional del Trabajo (OIT)
INEGI (Instituto Nacional de Estadística, Geografía e Informática) (varios años): Industria maquiladora de exportación, México, D.F.

Mertens, L. y L. Palomares (1988): El surgimiento del nuevo tipo de trabajador en la industria de alta tecnología: el caso de las electrónicas, E. Gutiérrez, Restructuración productiva y clase obrera, México, D.F., Siglo XXI.

Mortimore, M. y W. Peres (1998): Policy Competition for Foreign Direct Investment in the Caribbean Basin: Costa Rica, the Dominican Republic and Jamaica, serie Desarrollo productivo, N 49, LC/G.1991, Santiago de Chile, CEPAL.

Mortimore, M. y R. Zamora (1998): La competitividad internacional de la industria de prendas de vestir en Costa Rica, serie Desarrollo productivo, $\mathrm{N}^{\circ} 46$, Santiago de Chile, CEPAL.

Mortimore, M., H. Duthoo y J. A. Guerrero (1995): Informe sobre la competitividad internacional de las zonas francas en la República Dominicana, serie Desarrollo productivo, $\mathrm{N}^{\circ} 22$, Santiago de Chile, CEPAL, agosto.

OIT (Oficina Internacional del Trabajo) (1996): La situación sociolaboral en las zonas francas y empresas maquiladoras del Istmo Centroamericano y República Dominicana, San José, Costa Rica.

SECOFI (Secretaría de Comercio y Fomento Industrial) (1996): Programa de importación temporal para producir artículos de exportación, México, D.F.

Vicens, L., E. Martínez y M. Mortimore (1998): La competitividad internacional de la industria del vestuario de la República Dominicana, serie Desarrollo productivo, N 45, LC/G.1973, Santiago de Chile, CEPAL.

Wilson, P. (1990): The New Maquiladoras: Flexible Production in Low Wage Regions, Working paper series, $N^{\circ} 9$, Austin, Texas, Community and Regional Planning. 